\title{
A OPACIDADE DO ILUMINISMO: O RACISMO NA FILOSOFIA MODERNA
}

\author{
Érico Andrade* \\ ericoandrade@gmail.com
}

RESUMO O objetivo central do presente artigo é entender as razões filosóficas para o discurso racista no iluminismo. A minha hipótese é de que a filosofia colocou no mesmo patamar de certeza as verdades cientificas sobre os objetos naturais e o conhecimento dos diferentes povos. Com isso, ela se autorizou a traçar um horizonte impessoal e objetivo para o qual todos os povos deveriam caminhar no intuito de garantirem a maioridade da razão. Quando determinou o modelo europeu como esse horizonte, a filosofia moderna lançou bases para o etnocentrismo e para uma de suas consequências possíveis: o discurso racista. Acredito que com este texto é possivel tirar da sombra o tema do racismo na filosofia.

Palavras-chave Filosofia, ciência, iluminismo, racismo, razão.

ABSTRACT This paper seeks to understand the philosophical reasons for the racist discourse in the Enlightenment era. My hypothesis is that philosophy placed scientific truths on natural objects and knowledge of different peoples on the same level of certainty. With this, philosophy allowed itself to draw an impersonal and objective horizon to which all peoples should walk in order to assure the adulthood of reason. When philosophy determined the European model as that horizon, modern philosophy laid the foundations for ethnocentrism and

* Prof. Dr. Filosofia UFPE. Membro do Núcleo de Ética e Filosofia Política (NEFIPE), Projeto CNPq Universal: 482877/2013-8 Universal/2013. A crítica do uso da razão na filosofia utilitarista, que também é de certa forma herdeira do iluminismo, foi feita por mim em Andrade (2013). Agradeço as sugestões do(a) parecerista da Kriterion e dos colegas do NEFIPE. Artigo submetido em 22/03/2016 e aprovado em 05/05/2016. 
for one of its possible consequences: racist discourse. I believe that with this text it is possible to take the theme of racism in philosophy out of the shadows.

Keywords Science, philosophy, racism, enlightenment, reason.

\section{Introdução}

O presente texto não se insere diretamente no debate importante sobre o pós-colonialismo. Trata-se de um acerto de contas com a história da filosofia. Meu objetivo no presente artigo é fornecer argumentos de que o iluminismo substancializa uma compreensão da razão que outorga para si o direito de avaliar e legitimar a autoimagem dos povos em conformidade com uma visão etnocêntrica do mundo. Nesse sentido, vou usar de um modo estendido a compreensão do termo iluminismo. Tenho consciência da complexidade deste conceito que varia fortemente de autores para autores, mas entendo que o iluminismo designa a aposta de que o discurso racional, tomado como alicerce para a objetividade do conhecimento científico, teria a mesma objetividade para descrever e avaliar o aperfeiçoamento moral dos povos. Trata-se da fé, como diria Cassirer, "na unidade e imutabilidade da razão" (Cassirer, 1992, p. 23). Portanto, a minha hipótese é que o discurso iluminista (entendido aqui de modo geral como o discurso em que a razão é a determinação universal do que é o bem com vistas a um progresso moral e político qualitativo nos termos de Cassirer) sedimenta uma compreensão unilateral da razão, calcada na tese de que é possível transpor a objetividade do discurso científico para o discurso moral e político.

É evidente que os diversos filósofos citados no texto guardam diferentes concepções da razão (Hegel, por exemplo, foi crítico do iluminismo tal como ele fora concebido por alguns filósofos do século XVIII) e não há necessariamente entre os seus intérpretes uma concordância quanto à definição da razão usada por eles em seus diversos textos. Tenho consciência disso. No entanto, meu objetivo é mostrar que a objetividade do discurso científico autorizou uma compreensão unilateral da razão por meio da qual os filósofos modernos se sentiram autorizados a discursar sobre a natureza humana de modo análogo ao discurso científico sobre a natureza e o comportamento dos corpos físicos. ${ }^{1} \mathrm{E}$

1 Hegel efetivamente era um crítico da filosofia inglesa, sobretudo de Newton, que ele associava ao espírito experimental. De algum modo, ele sustentava que a explicação de Newton não esgotava a natureza racional do universo. A física newtoniana era muito quantitativa e pouco qualitativa, segundo Hegel. Isso pode ser visto em vários dos seus escritos sobre a filosofia da natureza, especialmente: "Dissertatio philosophica de 
nessa perspectiva que Cassirer afirma que "A filosofia do iluminismo considera que desde começo que os problemas da natureza e os da história formam uma unidade que é impossível desfazer arbitrariamente a fim de tratar à parte cada uma das frações" (Cassirer, 1992, pp. 269-270).

Nessa compreensão, a razão é apresentada como uma disposição reflexiva que possui uma dupla pretensão: por um lado, ser impessoal e, por outro, ser objetiva. Ela é impessoal porque não estaria subordinada às condições históricas (no máximo ela seria a própria expressão da história) em que o indivíduo se encontra quando fala em nome da razão. Ela seria objetiva porque poderia prescindir do consentimento intersubjetivo dos concernidos pelo discurso na medida em que outorga para si o poder de decidir sobre a legitimidade e validade da autoimagem produzida por todos os povos. Acredito que essa compreensão da razão autorizou o discurso iluminista, nos seus diferentes e variados matizes e que se estende, no presente texto, para críticos do iluminismo como Hegel, a estabelecer uma estrutura de hierarquia dos povos e, por conseguinte, a subsidiar um discurso de natureza racista, o qual se caracteriza, por um lado, pela homogeneização de diferentes culturas africanas e, por outro, pela associação do negro aos predicados normalmente usados para designar propriedades de animais e que demonstrariam a sua inaptidão essencial (biológica) para as tarefas ditas do espírito, como o Estado e a filosofia. Assim, ainda que o conceito de racismo seja de algum modo contemporâneo e ganhe uma extrema complexidade quanto ao seu significado, no século das luzes ele ganha terreno na associação do negro, tomado de modo homogêneo, a traços animalescos que demonstrariam uma inaptidão congênita para o desenvolvimento autônomo e pleno da razão.

O caminho para defender a minha tese pavimenta-se em duas direções. Primeiramente, vou mostrar que a origem da objetividade do discurso filosófico iluminista está na confiança de que a racionalidade do discurso científico pode ser transferida para o discurso moral, preservando a mesma objetividade das assertivas científicas e o seu mesmo poder de predição. Vou mostrar, portanto, que esse sucesso do empreendimento científico alimentou a tese de que poucas leis e uma gama restrita de proposições poderiam mapear e determinar todo comportamento humano, a exemplo das leis da mecânica. Num segundo momento, tenciono mostrar como o discurso iluminista financia uma compreensão unilateral da autonomia (centrada no modelo europeu) para retirar dos povos a legitimidade de constituírem a sua própria autoimagem e cuja consequência é

orbitis planetarum" ("A Órbita dos Planetas". Trad. Danilo Vaz e Paulo Menez. Rio de Janeiro: Confraria do Vento, 2015). Com efeito, Hegel não negou as descobertas de Newton, nem o poder de predição da física newtoniana. Sobre esse ponto, ver Andrade (2007). 
a legitimação do discurso racista. O etnocentrismo da filosofia serviu também de base para legitimar o discurso racista e o próprio discurso racista reforçou, pelo pressuposto dos padrões europeus como os únicos racionais e autônomos, a própria posição etnocêntrica.

Tenho convicção de que o discurso iluminista foi importante para o fortalecimento das instituições na Europa por meio da defesa de que os povos poderiam determinar as suas próprias leis e não estariam mais, por conseguinte, submetidos a leis que emanavam da vontade divina e às quais só algumas pessoas teriam um acesso privilegiado, sejam sacerdotes, reis ou mesmo um misto das duas coisas. Contudo, quando as luzes situam seu foco nas fronteiras de um continente, elas servem para ratificar estereótipos porque eclipsam a opinião dos que são estereotipados. Incorporando a razão em seu discurso, os iluministas fizeram do que não é o espelho da Europa a imagem do atraso, do desumano, que precisaria, na melhor das hipóteses, ser conduzido (adestrado) para se adequar ao modelo europeu. É nesse sentido preciso que gostaria de tecer uma crítica ao uso que o discurso iluminista faz da razão no intuito de mostrar como ele pode financiar o racismo e a própria servidão. Não quero afirmar que o iluminismo se prestou apenas a isso, mas gostaria de alertar que a servidão é, paradoxalmente, uma das consequências possíveis do empoderamento da razão como instância capaz de julgar a autonomia dos povos.

\section{Complexo de Narciso: a filosofia como imagem de si mesma}

Para a maioria dos pensadores do século XVIII, parecia claro que o acesso à natureza, que a ciência física havia propiciado, deveria agora ser seguido para a instauração de instituições sociais, políticas e econômicas que estariam em acordo com a natureza (Rorty, 1997, p. 38).

É por meio da razão que nos tornamos, para usarmos as palavras de Descartes, "mestres e senhores da natureza". Essa imagem ilustra que a centralidade do recurso à razão, como instância de validação da verdade, surge no discurso filosófico da era moderna, primeiramente, no seu aporte para o desenvolvimento técnico e científico cujo crescimento naquele momento alcançava escalas exponenciais. A razão tem o poder de reunir as diversas atividades científicas numa base comum e objetiva, inscrita na prerrogativa metodológica de que as mais variadas ciências são expressão de um mesmo processo racional; conduzido pela unidade do entendimento humano, ou, nas palavras de Descartes: todas as 
ciências: "são expressão da mesma sabedoria humana" (AT, X, p. 36). ${ }^{2}$ A ciência é uma atividade da razão humana que se projeta sobre a natureza para torná-la o seu espelho, de sorte que tudo aquilo que o ser humano toca transformar-se em racional, em sua autoimagem.

A razão que explica como os corpos naturais são governados e, consequentemente, podem ser dominados por técnicas, migra para a moral sobre a mesma prerrogativa de que podemos governar nossas ações por meio de um critério objetivo, um padrão invariável para todas as ações. Isso autoriza, por exemplo, Hobbes a usar o termo leis da natureza para se referir às suas leis morais. Ou seja, se a contingência dos fenômenos naturais é dominada pelo mecanicismo, que converte a sua diversidade de comportamento em padrões constantes e sincronizados pelas leis da física, a contingência dos fenômenos históricos, que fomenta diferentes culturas, expressas por diferentes modos de comportamento, pode ser domada por meio da padronização racional do horizonte para o qual devem tender os valores morais. Assim, os pressupostos metafísicos, que financiavam a confiança de que os homens poderiam por meio da mecânica conhecer os segredos de Deus, o modo pelo qual Deus arquitetou o universo ou o escreveu "em linguagem matemática” (“O Ensaiador”, Galileu), passam a lastrear a confiança de que homens podem transformar a promessa da vida celeste, propagada pela religião, num governo racional por meio do qual os homens expressariam a sua insociável sociabilidade (Kant, IHUC, "Quarta proposição"), ou, nas palavras de Leibniz: "um instinto geral de sociedade" (Leibniz, NEEH, I, cap. II, parágrafo 9). Ou seja, da metafísica à moral pode não existir um caminho linear, como desejavam alguns filósofos modernos, mas certamente existe uma via que é pavimentada pela aposta de que a razão pode ser a luz que esclarecerá os homens no que diz respeito aos segredos da harmonia dos astros, bem como no que concerne aos segredos do convívio harmônico dos homens na terra. A admiração pelas estrelas remete a harmonia dos céus à terra.

A centralidade da ciência como veículo da verdade decorre da convicção de que podemos antever o futuro, como se estivéssemos do ponto de vista divino, olhando toda a eternidade, desde que projetemos uma estrutura mecânica como a imagem do universo. Com a ciência os homens se assemelham a Deus no que diz respeito à capacidade de espelhar a harmonia dos corpos. Em nosso caso, a partir do olhar científico, visto que, diferentemente do olhar divino, o olhar humano reapresenta o mundo após um longo processo de depuração e

2 As obras clássicas serão citadas pelas iniciais em geral em português, ou pela notação mais habitual, como é o caso das obras de Descartes. 
aperfeiçoamentos dos sentidos, promovido pela razão, isto é, pela faculdade humana que é capaz de corrigir a percepção por meio da construção de modelos matemáticos. A confiança na ciência, que autoriza o ser humano a reconhecer na razão o elo comum com Deus, converte-se no âmbito moral em confiança na capacidade de aperfeiçoar os sentidos e controlar as paixões por meio da razão. Assim, independentemente das várias tendências que moldam o comportamento em sintonia com as nossas disposições sensíveis, a razão é capaz de produzir um conjunto de leis morais que não conhecem, tal como as leis da ciência, nenhum limite na particularidade dos corpos; no caso específico das leis morais, na particularidade da vontade. Se a vontade é, como afirma Kant, "determinável pela lei moral", ela tem como objeto necessário a "realização do sumo bem no mundo" (Kant, CRPA, dialética da RPP, IV, p. 197). Pouco importa para a ciência se se trata de corpos celestes ou terrestres, as leis da natureza são as mesmas (ver: Descartes, "Mundo"). Igualmente, importa muito pouco às especificidades dos comportamentos realizados em diversas culturas em face da capacidade da razão de instituir uma unidade racional dos códigos morais na forma de um sumo bem ou de algo equivalente. Essa confiança na moral universal assume a forma de uma aposta na objetividade das crenças morais cuja matriz propulsora é a razão. Quanto mais próxima de uma atitude racional, mais objetiva seria uma crença moral. Em outras palavras, se a racionalidade da natureza estava na sua uniformidade e constância, prescritas pelas leis do mecanicismo, nas relações humanas a razão promove uma visão progressiva dos fenômenos sociais, aparentemente desconexos, que são julgados de acordo com a adequação dos seus juízos morais à objetividade das crenças morais, ditas racionais.

A razão passa a ser compreendida, na forma da liberdade em Hegel, como uma direção para a qual as ações humanas convergem silenciosamente e de modo inexorável no sentido de promoverem autoconhecimento do espírito (Hegel, FH, pp. 24-25). Nesses termos, o universal, segundo Hegel, "está nos fins particulares e se realiza por intermédio deles" (Hegel, FH, p. 30). A história, portanto, não é uma "necessidade abstrata e irracional de um destino cego" (Hegel, FD, parágrafo 342, p. 306). Ou, nas palavras de um dos seus importantes intérpretes: "A necessidade histórica inclui nela tanto o ideal que ilumina seu movimento quanto o processo subterrâneo cego que se passa na massa humana" (Bourgeois, 2000, p. 66). Isto é, assim como os fenômenos da natureza, os acontecimentos humanos não são desconexos e arbitrários, mas seguem um propósito velado porque guiam os seres humanos na direção inexorável do progresso moral.

Os homens novamente põem-se do ponto de vista divino, mas agora não somente para traduzir os comandos divinos em leis da natureza. A razão não 
exerce apenas o poder de contemplar as verdades da natureza. Ela tem um caráter prático inscrito na sua condição de governar a ação humana em busca de um processo de aperfeiçoamento moral. A razão permite aos homens projetar seu próprio desenvolvimento moral ao longo da história, ou mesmo infinitamente, segundo Kant (Kant, CRPP, IV, p. 198), como um contínuo e ininterrupto processo de aperfeiçoamento moral. As mudanças que ocorrem na história, afirma Hegel: "são caracterizadas igualmente como um progresso para o melhor, o mais perfeito" (Hegel, FH, p. 53). Afinal, a razão é, ainda segundo Hegel: "compreensão da obra divina" (Hegel, FH, p. 38). Os caminhos que desviam a história de um curso uniforme ou linear são na verdade passos diferentes em direção a um mesmo propósito. Nesse sentido, a divergência entre as culturas não pode elidir a convergência que elas guardam quanto à contínua busca pela "maioridade" da razão. Toda cultura deseja a emancipação, sentencia o discurso iluminista no seu sentido lato. Desejamos ser a imagem e semelhança de Deus, que é capaz de determinar as suas próprias leis. A divindade da lei moral está na autonomia racional dos homens, que independentemente da cultura, podem se mover, ainda que infinitamente, na direção do autoconhecimento e do pleno controle de si mesmos (Kant, CRPP, p. 198).

Se a legitimidade do mecanicismo podia ser atestada pela previsibilidade dos fenômenos naturais e pelo incremento exponencial da técnica, no âmbito moral era necessário mostrar que os povos convergiam para um mesmo reconhecimento de si mesmos como humanos e que cada etapa de suas histórias era a prova do progresso humano. A filosofia coloca-se no âmbito da atividade investigativa da razão como a disciplina que tem o poder de antever o fio condutor da história. Isso porque ela se estrutura sobre uma base objetiva que a habilita a garantir a impessoalidade na construção do conhecimento moral e científico. Ou seja, a validade do conhecimento filosófico consiste no fato de ele ser supostamente autônomo em relação às crenças dos que o produzem, os filósofos, as pessoas que o fazem, assim como o discurso científico é independente da crença dos cientistas em entidades transcendentais ou de qualquer outra natureza. A objetividade da ciência sobrevive a despeito das crenças particulares dos cientistas. A despeito de achar a circunferência a figura perfeita e crer no valor simbólico das figuras geométricas, Kepler, por exemplo, foi obrigado a reconhecer, depois de muito relutar, que a órbita dos planetas, segundo os seus próprios cálculos, era elíptica (Ver: Andrade, 2006, p. 62). O conhecimento racional da moralidade poderia operar com esse grau de objetividade e se desvincular da rede de valores morais na qual está inserida o filósofo. ${ }^{3}$

3 A eleição da matemática, por parte de vários filósofos modernos, como modelo metodológico para o discurso filosófico assenta-se nesta compreensão. Com efeito, independentemente de sua estrutura matemática, que 
A imagem do mecanicismo como o espelho da natureza é transferida pela filosofia à história na forma do humanismo, que traduz o modo mais acabado de autonomia. Se não é possível se autodeterminar como Deus, que institui as suas leis fora do tempo, é possível fazer do tempo o espelho de um único processo de autodeterminação. As engrenagens e os comandos mecânicos, que mostram que a história do universo é a repetição de um mesmo padrão - não aleatório e constante -, são substituídos por leis e códigos morais que humanizam a história por meio da certeza de que a procura pela autodeterminação se repete ao longo da história. As culturas passam a ser diferentes expressões ou momentos de um mesmo processo de aperfeiçoamento moral que institui gradações entre as diferentes culturas em sintonia com o maior grau de racionalidade de sua respectiva organização social, especialmente na forma do Estado, visto que, segundo Hegel: "Na história universal só se pode falar de povos que formaram um Estado" (Hegel, FH, p. 39). Nesse sentido, a filosofia da história e da política de Hegel, assere Taylor: "fundem-se em sua visão ontológica" (Taylor, 2005, p. 95).

Nesse contexto, o humanismo encerra a lente ideal que uniformiza num mesmo mosaico o feixe de múltiplas culturas na medida em que estabelece um único propósito para a espécie humana. Assim, os diversos fragmentos da história humana compõem uma mesma imagem em construção. As diferentes etapas da construção são as diferentes etapas do progresso. Os homens deixam de ser a imagem de Deus para serem a imagem de si mesmos porque eles reconhecem que a luz responsável pela reflexão de qualquer imagem repousa na própria condição humana, reside na razão. O humanismo expressa a conversão da religião em filosofia porque, para nos assemelharmos a Deus, não é mais necessário reconhecer a inferioridade humana em face da grandeza divina na forma da sujeição do homem ao mistério divino. A filosofia assume o papel da religião porque nos liga a Deus por um aspecto positivo, a saber, a razão. Partilhamos com Deus o poder de nos determinarmos pela razão. Isso conforta a finitude da vida humana por colocar os homens no interstício entre os deuses e os animais.

Essa convicção indica uma estrutura que só admite uma contraprova no modelo da impessoalidade, por meio do próprio discurso filosófico, isto é, todas as variáveis que marcam o discurso filosófico, como as crenças religiosas, culturais e sociais de modo geral, são tomadas como expressões irrelevantes para julgar as teorias filosóficas. A filosofia só está sob o escrutínio de si mesma. Só um argumento filosófico poderia se contrapor a um argumento filosófico. 
Por conseguinte, o acesso da filosofia à natureza humana não é posto em dúvida e o discurso filosófico passa a ser julgado apenas por seus critérios internos ou metafilosóficos como coerência, abrangência, diálogo com a tradição, simplicidade etc.. Desse modo, na filosofia moderna iluminista, a razão é convocada para falar de si mesma para si mesma. Ela é o seu próprio tribunal e não reconhece nenhuma outra instância como legítima para fazer seu próprio julgamento. A "Crítica da Razão Pura" encerra esta ideia quando convida a razão a "empreender a mais difícil de suas tarefas, a do conhecimento de si e da constituição de um tribunal que lhe assegure pretensões legítimas" (Kant, CRP, Prefácio 11-12, p. 5). Esse tribunal, continua Kant, não é instituído por uma decisão arbitrária (isto é, pessoal), "mas em nome das suas leis eternas e imutáveis" (Kant, CRP, Prefácio 11-12, p. 5). Em outras palavras, a legitimidade do pensamento filosófico obedece a uma dinâmica interna, visto que os limites impostos à razão são outorgados pela própria razão. Esse caráter autocentrado e circular do discurso filosófico traduz-se na forma de um sistema que mantém no seu domínio todo conhecimento humano; articulado e justificado por um rede de princípios racionais.

A noção de sistema como um conjunto de proposições interconectadas e ordenadas por uma rede de princípios racionais é alimentada pelo pressuposto de que a razão se move na forma de diferentes vestes, mas com um mesmo propósito de tornar o mundo esclarecido. O sistema não é sinônimo de uniformidade, nem é uma forma de demarcar um limite para a atividade filosófica. Ele é, pelo contrário, um processo, uma abertura sem limites para a compreensão dos fenômenos na forma de um aperfeiçoamento racional que converte a história em realização dos propósitos da astuciosa razão. O sistema encerra a ideia de que a filosofia se autojustifica e de que todas as diferentes ramificações do projeto filosófico (ético, estético, político e epistemológico) remetem-se a uma mesma raiz racional. A unidade do conhecimento é a unidade da razão e possivelmente é a unidade que garante a identificação dos povos para além de suas diferenças históricas. O nosso reconhecimento como humanos é o primeiro passo em direção à maioridade da razão.

A confiança do discurso filosófico iluminista na razão é amparada pela ideia de que ela promove na forma de ciência o domínio sobre a natureza e pela prerrogativa de que ela é acessível a todos os seres humanos; dispostos a agirem em conformidade com a sua própria autonomia. No âmbito moral a confiança repousa, portanto, na convicção de que o uso correto da razão conduz os seres humanos não apenas à autonomia, mas, sobretudo, à construção de um aperfeiçoamento moral e de um horizonte político comum e, por isso, universal. A bandeira do iluminismo flameja com a certeza de que o fim da servidão encontra-se num processo de racionalização dos costumes dos povos. 
Resta saber, contudo, se o discurso iluminista não esconde por trás de sua couraça de objetividade e impessoalidade uma forma de dominação sutil que retira o poder dos povos não "esclarecidos" de se autodeterminarem segundo seus próprios padrões.

\section{À sobra da luz}

A menoridade é a incapacidade de se servir de seu próprio entendimento sem a tutela de um outro Kant. O que é o Esclarecimento? A essas determinações universais, baseadas na consciência presente, nas leis da natureza e em seu conteúdo o que é o justo e o bom, chamou-se de razão; a validade dessas leis chamou-se iluminismo (Hegel, FH, p. 362).

Por enquanto, meu artigo concentrou-se em apresentar a origem da confiança de que a filosofia garante a nossa crença numa natureza humana racional. Nessa confiança estão presentes duas certezas correlacionadas: a filosofia pode acessar a natureza humana e esse acesso é franqueado a todo homem que se dispõe a pensar por si mesmo. Ou seja, a autonomia referente à capacidade de se autodeterminar é decorrência da convicção de que os homens podem domar a sua história por meio da introdução de uma unidade racional dos seus valores que os guiará em direção ao aperfeiçoamento moral. Esse aperfeiçoamento espelha uma legislação racional feita pelos homens e para os homens. Em outras palavras, com a razão os homens conferem para si mesmos a confiança de que podem servir apenas a si mesmos. O discurso filosófico iluminista esvazia os céus para povoar a história com a ideia de que a racionalidade torna possível o propósito da nossa natureza de viver o reino dos fins.

Com efeito, considero importante investigar se um discurso marcado por uma compreensão unilateral da racionalidade pode ser entendido unicamente como emancipatório. Será que todas as formas de servidão podem ser eliminadas com o iluminismo?

O discurso filosófico iluminista defende o governo dos homens para os homens por meio da introdução de códigos que expressam não propriamente a soma das vontades particulares, mas uma disposição racional que conduz os povos para uma vida boa. O caminho da emancipação é o caminho da racionalização das instituições e dos costumes. Todavia, da abstração do modelo filosófico à materialização da razão o caminho não é uniforme. Ele é traçado com a alegação de que a incorporação da racionalidade é gradual e requer algumas posições (sacrifícios) necessárias, como, por exemplo, a uniformização, ainda que mediada, em alguns casos, por um processo dialético, de interesses particulares, em detrimento das múltiplas motivações que impulsionam os seres 
humanos à ação. Apenas os povos que se determinam pela razão podem romper as amarras da servidão presente nos interesses contingentes de cada indivíduo e se constituírem, de fato, como uma unidade política cuja forma mais bem acabada é, segundo Hegel: "a moralidade objetiva" incorporada na noção de Estado (Hegel, FH, p. 39).

A impessoalidade (indiferença às condições históricas nas quais se encontra a pessoa responsável pelo discurso filosófico) e a objetividade (validade per $s e$ ), que marcam a razão na modernidade, passam a legitimar uma avaliação da condição das diferentes culturas em relação ao seu processo de autodeterminação. O caráter impessoal e objetivo do discurso iluminista investe-o da prerrogativa de avaliar o grau de aperfeiçoamento moral dos diferentes povos. A impessoalidade e a objetividade do discurso filosófico autorizam-no a traçar uma hierarquia entre as culturas que não é, segundo ele, arbitrária, mas expressa de forma neutra o desenvolvimento do ser humano em busca de sua autodeterminação. O discurso iluminista não se sente inibido para falar de outros povos, dos quais os filósofos iluministas tinham pouco conhecimento, visto que seu caráter objetivo e neutro indica que ele fala do ponto de vista da humanidade para a humanidade. Fala-se da natureza humana como analogamente a física fala dos corpos, supostamente com o mesmo grau de objetividade.

Entretanto, quando o discurso iluminista não confere aos indivíduos o poder de decidir, de modo legítimo, se a sua autoimagem corresponde à autoderminação da razão, ele infringe paradoxalmente a autonomia dos povos porque lhes retira do direito de tomar a imagem de si mesmos como legítima autoimagem. Vou mostrar agora que a defesa da autodeterminação dos povos esbarra numa compreensão unilateral da razão que faculta a um povo o modelo ou padrão legítimo de autodeterminação, de autonomia.

O padrão da avaliação iluminista não é uma abstração. Ele repousa na convicção de que o caminho que todos os povos devem seguir para se autodeterminarem foi desbravado pela Europa. Por conseguinte, a autonomia estrutura-se não apenas como um critério impessoal e objetivo, como parece sustentar o discurso filosófico iluminista, mas como um modo de legitimar uma autoimagem em detrimento das demais. Ou seja, a impessoalidade e a objetividade do discurso filosófico iluminista parecem encontrar severos limites quando ele julga outros povos sem considerar a imagem que eles fazem de si mesmos, a sua autoimagem.

Nesses termos as seguintes passagens, que expressam uma convergência profunda entre diversos filósofos iluministas; capaz de atravessar as barreiras, nem sempre impermeáveis, que separam empiristas e idealistas, quanto ao povo sobre o qual cai a prerrogativa da falta de autonomia. Da compreensão unilateral 
da razão - acoplada ao modelo europeu - segue-se uma das faces mais cruéis do etnocentrismo: o racismo. Os que estão na menoridade da razão têm uma cor definida e servem para mostrar que as luzes dos diversos discursos iluministas paradoxalmente deixam na sombra tudo aquilo que não for expressão da cultura europeia, especialmente, claro, o continente "negro":

a principal característica dos negros é que sua consciência ainda não atingiu a intuição de qualquer objetividade fixa, como Deus, como leis, pelas quais o homem se encontraria com a própria vontade, e onde ele teria uma ideia geral de sua essência [...] O negro representa, como já foi dito o homem natural, selvagem e indomável. Devemos nos livrar de toda reverência, de toda moralidade e de tudo o que chamamos sentimento, para realmente compreendê-lo. Neles, nada evoca a ideia do caráter humano [...] A carência de valor dos homens chega a ser inacreditável (Hegel, FH, pp. 83-86).

O seu rosto [negro] parece-nos horrível, a sua inteligência parece-nos limitada, os seus gostos são vis, pouco nos falta para que o tomemos por um ser intermediário entre o animal e o homem (Tocqueville, 1977, p. 262).

Os negros da África não possuem, por natureza, nenhum sentimento que se eleve acima do ridículo. O senhor Hume desafia qualquer um a citar um único exemplo em que um Negro tenha mostrado talentos, e afirma: dentre os milhões de pretos que foram deportados de seus países, não obstante muitos deles terem sido postos em liberdade, não se encontrou um único sequer que apresentasse algo grandioso na arte ou na ciência, ou em qualquer outra aptidão; já entre os brancos, constantemente arrojam-se aqueles que, saídos da plebe mais baixa, adquirem no mundo certo prestígio, por força de dons excelentes. Tão essencial é a diferença entre essas duas raças humanas, que parece ser tão grande em relação às capacidades mentais quanto à diferença de cores. [...] Os negros são muito vaidosos, mas à sua própria maneira, e tão matraqueadores, que se deve dispersá-los a pauladas (Kant, 1990, pp. 75-76).

Eu estou em condições de suspeitar serem os negros naturalmente inferiores aos brancos. Praticamente não houve nações civilizadas de tal compleição, nem mesmo qualquer indivíduo de destaque, seja em ações seja em investigação teórica. [...] Tal diferença uniforme e constante não poderia ocorrer, em tantos países e épocas, se a natureza não tivesse feito uma distinção original entre essas raças de homens. Sem citar as nossas colônias, há escravos negros dispersos por toda a Europa, dos quais ninguém alguma vez descobriu quaisquer sinais de criatividade, embora pessoas de baixa condição, sem educação, venham a progredir entre nós, e destaquem-se em cada profissão. $\mathrm{Na}$ Jamaica, realmente, falam de um negro de posição e estudo, mas provavelmente ele é admirado por realização muito limitada como um papagaio, que fala umas poucas palavras claramente (Hume, 1875, p. 252, textos políticos e morais).

Os percebemos com os mesmos olhos que vemos os negros, como uma espécie de homem inferior (Voltaire, 1963, p. 294).

Essas passagens são geralmente obliteradas pelos intérpretes e historiadores da filosofia que preferem concebê-las como um excesso periférico nas obras 
filosóficas ou um detalhe biográfico pouco relevante para a reflexão produzida por esses autores. No máximo, diz-se que o racismo era o espírito do tempo e que os filósofos não poderiam fugir dele. Sei que para cada pensador desse existem estudos que tentam atenuar, ${ }^{4}$ nos casos mais otimistas, tornar bastante residual o racismo, mas gostaria de insistir que o racismo é de algum modo uma decorrência do discurso iluminista. ${ }^{5}$ Vou mostra que, independentemente de o contexto histórico ser hegemonicamente racista, o discurso iluminista, quando se furta a remeter a cada povo o poder de fazer sua autoimagem, autoriza o racismo, entendido como a predicação perjuriosa de uma cultura ou de um povo, como exposto na introdução do presente artigo, sem o assentimento desse povo.

O discurso racista é financiado pela tese de que, por não terem produzido sistemas de lei e reflexão semelhantes aos padrões europeus, visto que "a principal característica dos negros é que sua consciência ainda não atingiu a intuição de qualquer objetividade fixa, como Deus, como leis" (Hegel, FH, p. 84), os negros estariam numa espécie de condição inferior. ${ }^{6} \mathrm{O}$ que governa a assertiva de Hegel é a convicção de que não há caminho para autodeterminação que não seja o caminho percorrido pelos europeus que determina o que é grandioso. Assim, ainda que a seta do tempo possa ser lida na obra de Hegel, segundo Safatle e outros intérpretes do filósofo, como uma seta para trás; responsável por contar uma narrativa possível da história a partir de uma costura racional dos fatos que

4 Na sua introdução à tradução do texto de Kant sobre as raças, citado no meu artigo, A. Hahn recorre à seguinte citação de Zöller e Wilson, "a teoria de Kant da história natural das espécies humanas não tem encontrado a contínua atenção acadêmica que ela merece, em termos de seu conteúdo filosófico e sua contribuição para a história e a filosofia da ciência" (ZÖLLER, Günter; WILSON, Holly. Introduction to "Of de different races of human beings". In: KANT, I. Anthropology, history, and education, 2009, p. 497 - nota 4). (Hahn, 2010, p. 8). É notável o modo eufemístico com o qual os comentadores citados por Hahn redigem o seu texto. O que eles chamam de polêmico é uma perspectiva racista. Para o tradutor, o texto kantiano seria um texto iminentemente de geografia: assim, tendo em vista que a geografia física se ocupa apenas das peculiaridades (Merkwürdigkeiten) da natureza, o homem é tomado comparativamente por ela, em diversas regiões da Terra, tão somente segundo a diferença de sua forma (Bildung) natural e cor (Hahn, 2010, p. 6). O problema, contudo, é inferir da cor, ou mesmo do lugar, modos de comportamentos que são subsídios para diminuir certa etnia. Ricardo Terra sustenta que os estudos de Kant a respeito das raças e da origem dos homens de forma alguma comprometem o ponto de vista cosmopolita de sua teoria. As passagens com teor racista indicam o tipo de fonte empírica de que Kant dispunha e não têm consequências para a sua filosofia (Terra, 2010).

5 O recente texto de Lepe-Carrión (2014) é um dos poucos publicados em revistas de filosofia que associa a teoria kantiana das raças ao discurso imperialista. Sobre a influência do discurso kantiano no debate sobre a colonização: Gonçálves (2015).

6 Purtschert faz um mapeamento das críticas ao racismo presente na filosofia de Hegel e divide-as em dois blocos: "it identifies Hegel's racist assumptions, his misjudg-ment of foreign cultures, or his refusal to value non-European contributions to human development" (Purtschert, 2010, p. 1041). Para Hegel, continua a autora, a África subsaariana (embora essa distinção geográfica da África não esteja clara no texto) seria contrária ao espírito e, por não ter instituições, estaria numa condição de difícil distinção em relação à natureza. A África estaria fora da história para Hegel (Purtschert, 2010, p. 1045). De algum modo, meu artigo pretende mostrar que essas duas críticas se complementam no sentido de que o etnocentrismo é o alicerce para o racismo e o próprio racismo reforça posições etnocêntricas, o que parece ser, aliás, a posição da autora supracitada. 
ocorreram segundo uma lógica da plasticidade, da adequação e resignificação do acontecido, ela indica (e neste ponto coincide com a compreensão kantiana da história) que o caminho - esperado e almejado no caso de Kant - para o aperfeiçoamento moral passa por um processo de racionalização da vida e dos costumes. ${ }^{7}$ Esse processo se encerra nos limites do continente europeu e serve como uma espécie de régua responsável por escalonar o grau de "evolução" de cada cultura. O grau máximo é o que se apresenta na Europa e o mínimo parece se localizar no continente africano.

Essa posição hegeliana já encontrava eco na convicção de Hume de que os negros seriam incapazes de produzir arte e ciência do mesmo modo que os europeus. Nesses termos, a história funcionaria segundo a mesma lógica do hábito ou costume, presente na epistemologia desse autor, e atestar-nos-ia, pelo padrão de repetição, que os negros não conseguem formular investigações, nem produzir alta cultura. Mesmo quando habitam o mesmo terreno dos europeus não é possível, ainda segundo Hume: "descobrir qualquer sinal quaisquer sinal de criatividade" (Hume, 1875, p.252), sobretudo quando comparados com europeus nas mesmas condições sociais. Kant acompanha Hume quando afirma que os negros não foram capazes de mostrar qualquer talento e, quando postos em liberdade, não foram capazes de "algo grandioso na arte e na ciência" (Kant, 1990, p.75-76). Com efeito, quando se diz que os negros nunca fizeram algo grandioso, o padrão que se toma é claramente o europeu, responsável por forçar os negros, como alerta Taylor em outro contexto (Taylor, 2000, p. 273), a pautarem as suas produções culturais nos padrões existentes, pois essa seria a única forma de serem reconhecidos como pessoas autônomas o suficiente para agirem de modo racional.

Desse modo, a autodeterminação não autoriza que os povos, diferentes culturas, possam estabelecer seus critérios para reconhecerem a sua liberdade e a sua emancipação, visto que os filósofos outorgam-se o direito de serem, em nome da razão, o tribunal que decide quais os povos próximos da emancipação ou mesmo emancipados. Em outras palavras, apenas a produção cultural realizada no interior da cultura que proclama o discurso iluminista como o espelho do humano é o tribunal legítimo para falar em termos de autodeterminação. Assim, a determinação de um único caminho seguro para a maioridade da razão,

7 Vários autores contemporâneos resgatam aspectos de uma virada afetiva na filosofia do Hegel. Notadamente os trabalhos de Butler, Safatle, Barreto Campello e Honneth. Essas leituras podem ser compreendidas como um contraponto à leitura de Heidegger, que denuncia um forte aspecto metafísico na filosofia de Hegel. Não tenho problemas em reconhecer a validade dessas leituras, mas não acredito que elas possam isentar Hegel quanto à assimilação da tese de que um discurso racional pode determinar a natureza do bem e a autoimagem dos povos a despeito das pessoas concernidas pelo discurso. 
prescrita pelo discurso iluminista, serve como subterfúgio para alocar outros povos num patamar inferior. Neste contexto, um grave problema do discurso iluminista é que ele reifica a razão e confere-lhe um estatuto próprio capaz de converter padrões culturais contingentes - os padrões europeus - em padrões universais para os quais não há escolha por parte das outras culturas senão a sua aceitação, sob pena de não estarem na direção do horizonte da racionalidade. Nesses termos, o etnocentrismo dá lugar ao racismo.

A atitude unilateral e, por isso, etnocêntrica, de outorgar para si o direito de classificar os povos expande-se - na sua forma mais radical -, para prejulgar que os negros estariam mais próximos dos animais do que propriamente dos demais seres humanos. Quando Voltaire afirma que os negros são inferiores, posição seguida por outros filósofos iluministas (Kant, 1990, p. 167; Hume, 1875, p. 252; Tocqueville, 1977, p. 262; Hegel, FH, p. 75), em relação à raça branca, ele aproxima-os, sub-repticiamente, dos animais, que não são capazes de autodeterminar-se. Com isso, os negros perdem o direito de autodeterminar a imagem de si mesmos e também de autodeterminarem-se como um todo, porque não são humanos plenamente e precisam, portanto, da tutela de outro povo, para agirem racionalmente, assim como um animal precisa de um adestrador para agir corretamente. Em outras palavras, o discurso iluminista traça uma relação entre os negros [invariavelmente chamados de selvagens, próximos, segundo Voltaire, dos rinocerontes e elefantes (Voltaire, 1963, p. 34)] e os animais, no intuito de mostrar que os negros não podem, assim como os animais, galgar autonomia por si mesmos. Nesses termos, Hegel, quando tece comentários sobre os sul-americanos, fruto da mistura com negros, alerta para a necessidade dos europeus de "incutir-lhes uma dignidade própria" (Hegel, FH, p. 75). Por essas razões, é necessário guiar os negros por meio do esclarecimento de sua condição quase animal ou dissolver a sua cultura para que a inexorável marcha do progresso não conheça limites. Em todos os casos, a dominação não é estranha à razão iluminista, porque ela é uma consequência muito provável para "salvar" os negros da selvageria que lhes é imposta por sua condição subumana.

Assim, a animalização do negro consiste em uma estratégia de justificar a servidão, uma vez que é perfeitamente aconselhável que ele seja tutelado por alguém cuja maioridade da razão traduza a capacidade de se autogovernar e, por conseguinte, governar quem não é capaz de fazer isso por si mesmo. $\mathrm{Ou}$ seja, quando o discurso filosófico, propagado por filósofos iluministas em certos contextos, assere a validade da tese de que os negros devem ser tratados, nas palavras de Kant, a pauladas, visto que, de algum modo, eles não teriam a coragem de se servirem do seu próprio entendimento no que consiste, aliás, a exigência kantiana para a liberdade, ele subsidia uma justificativa para a 
servidão na forma de uma tutela que poderia domar os negros e mostrar-lhes o único caminho seguro para o progresso.

Nessa perspectiva, ainda que vários filósofos iluministas admitam que a escravidão seja, por si só, injusta, não parece grave que a escravidão incida sobre os negros, considerando que se trata de uma subespécie humana. Hegel, por exemplo, sustenta, tendo implícita a ideia de tutoria, que o fim da escravidão deve ser gradual: "[...] a abolição progressiva da escravatura é algo mais apropriado e correto do que a sua abrupta anulação" (Hegel, FH, p. 88). Por conseguinte, a suposta inferioridade do negro em relação aos padrões europeus justifica, para alguns iluministas, a escravidão, ou, pelo menos, a sua continuidade até que os europeus tenham ensinado aos negros o caminho para a emancipação. Nessa mesma direção, ainda que Voltaire sustentasse certa fraternidade entre as raças e fosse um árduo defensor da liberdade, não hesitou em condenar as vítimas, os negros, no sentido de criminalizá-los por serem escravos: "um povo que trafica seus filhos é mais condenável do que o comprador", apoiando-se, para tanto, na tese de que "aquele que se entrega a um mestre nasceu para ter um" (Voltaire, 1963, p. 807). A atuação de alguns negros, de alguns países da África, de traficar escravos é tomada como uma justificativa para legar aos negros, de modo geral, uma condição subalterna porque incapaz congenitamente de se autodeterminarem. Em outras palavras, é notável que o racismo está presente na forma de designar diversos povos, com diferenças culturais acentuadas entre si, como "negros". Com efeito, tomar um continente inteiro a partir de alguns casos (em que havia, por exemplo, alguns negros que escravizavam e vendiam outros negros (Hegel, FH, p. 86), sem imputar a culpa dos europeus que viviam do tráfico de escravos não apenas é uma falácia como revela a face cruel do discurso iluminista.

A raiz da convicção de que a autonomia da razão efetiva-se por um processo de racionalização dos costumes e das instituições reside na aposta de que o acesso à razão é franqueado a qualquer indivíduo, de modo quase uniforme, o que ratifica que os negros portam uma dificuldade congênita, visto que eles não conseguem realizar o propósito da razão de instituir uma vida racional. Eles precisariam de tutores. A falta de emancipação dos negros, segundo os critérios iluministas, não se constitui numa contraprova do discurso iluminista, no sentido de alertar para o fato de que as organizações sociais não precisam seguir um mesmo padrão, mas, pelo contrário, segundo os filósofos das luzes, a razão que ilumina a todos não tem luz própria no continente africano. Essa certeza assenta-se na suposta capacidade da razão de determinar universalmente a natureza do bem e o caminho, único, para alcançá-lo.

Nesse sentido, o caráter supostamente objetivo do discurso filosófico iluminista libera-o do assentimento intersubjetivo à proporção que serve como 
subterfúgio para esconder a sua conotação eurocêntrica e, consequentemente, racista. A objetividade do discurso iluminista é comprometida quando o discurso toma pessoas de um continente inteiro, com as mais variadas especificidades, como a antípoda dos seres plenamente racionais. Parte dos filósofos que fizeram esse discurso conheciam muito pouco a história da África ou baseavam-se em fontes tanto questionáveis quanto escassas, mas estavam autorizados, pela suposta objetividade filosófica da razão, a classificá-los como selvagens, preguiçosos e inferiores ou, nas palavras de Kant: indolentes, moles e desocupados.

O pressuposto de que a razão é acessível a todos de modo uniforme e o de que ela é a forma legítima de definir a natureza humana serviram de argumentos para classificar os negros como subumanos, uma vez que eles não se adequavam aos padrões europeus por serem preguiçosos ou indispostos ao exercício da liberdade. Por isso, concluo que o discurso da servidão não é um acidente ou desvio do propósito do discurso iluminista, mas se apresenta como uma consequência muito provável de uma razão que não reconhece outra forma de vida que não seja o seu espelho. A gravidade desse ensimesmamento da razão e de sua substancialização como padrão de comportamento da conduta humana não se reduz apenas ao processo de clausura cultural, ao qual está submetido o discurso iluminista, profundamente etnocêntrico, como mostrei, mas se estende para a ideia de que a natureza humana define-se de modo unilateral, por meio de uma discussão filosófica, e, por conseguinte, independentemente do assentimento dos concernidos pelo discurso. Se a razão não se transforma numa estrutura pública, na qual os indivíduos apresentam seus argumentos como perspectivas abertas sobre as diversas possibilidades de se interpretar o fenômeno humano, ela corre o risco de ser o anteparo da servidão, porque sedimenta uma perspectiva sobre a natureza humana como a única possível.

\section{Referências}

ANDRADE, É. “O homem vazio: uma crítica ao utilitarismo". Trans/Form/Ação, Marília, (impresso) Vol. 26, pp. 105-121, 2013.

. "Uma crítica à teoria da complexidade proposta por Edgar Morin". Dissertatio, Nr. 26, pp. 167-187, 2007.

."Le rôle de la méthode dans la constitution de la physique cartésienne". Paris:

Sorbonne, 2006.

BOURGEOIS, B. O pensamento político de Hegel. Porto Alegre: Unisinos, 2000.

DESCARTES, R. “O Mundo ou Tratado da Luz”. Comentário, introdução e tradução de É. Andrade. São Paulo: Hedra, 2008.

Vrin, 1986.

"Euvres de Descartes". Org. C. Adam et P. Tannery. 12 Vol. 2. ed. Paris: 
GALILÉE, G. “Essayeur”. In: Dialogues et lettres choisies. Tradução de P.-H. Michel. Paris: Hermann, 1996.

GONÇÁLVES, R J. "A superioridade racial em Imanuel Kant: as justificações da dominação europeia e as suas implicações na América Latina.” Kínesis, Vol. VII, Nr. 13, pp. 179-195, julho 2015.

HAHN, A. "As diferentes raças humanas". Estudo e tradução A. Hanh. Kant e-Prints, Campinas, Série 2, Vol. 5, Nr. 5 (número especial), pp. 04-09, julho-dezembro, 2010. HEGEL, G. W. "Dissertatio philosophica de orbitis planetarum. A Órbita dos Planetas”. Trad. D. Vaz e P. Menez. Rio de Janeiro: Confraria do Vento, 2015. . "Filosofia do direito". São Paulo/São Leopoldo: Loyla/Unisinos, 2009. "Filosofia da História". Brasília: Ed. UnB, 1999.

HOBBES, T. Elementos de Filosofia, Primeira seção. Sobre o corpo. Parte I: computação ou lógica. Campinas: IFCH/UNICAMP, 2005.

HUME, D. (1748). "Of National Characters". In: D. Hume. Essays: Moral, Political and Literary. Editado por T. H. Green e T. Grose. London: Longmans, Green and Co., 1875. Vol. 1.

KANT, I. "Ideia de uma história universal do ponto de vista cosmopolita". Tradução de Ricardo Terra. São Paulo: Martins Fontes, 2010.

. "Crítica da Razão Pura". Lisboa: Fundação Calouste Gulbenkian, 2005.

"Crítica da Razão Prática". Tradução de Valério Rohden. São Paulo: Martins

Fontes, 2002.

. "Observation sur le sentiment du beau et du sublime”. Paris: Flamarion, 1990. . "Resposta à questão: 'O que é Esclarecimento?”. Tradução de Vinícius Figueiredo. Disponível em: https://www.academia.edu/7894936/I._KANT_Resposta_\%C3\%A0 quest $\% \mathrm{C} 3 \% \mathrm{~A} 3 \mathrm{o} \_\mathrm{O} \_q u e \_\mathrm{C} 3 \% \mathrm{~A} 9$ Esclarecimento_Introdu $\% \mathrm{C} 3 \% \mathrm{~A} 7 \% \mathrm{C} 3 \% \mathrm{~A} 3 \mathrm{o}$ tradu $\% \mathrm{C} 3 \% \mathrm{~A} 7 \% \mathrm{C} 3 \% \mathrm{~A} 3 \mathrm{o} \_$e_notas_por_Vinicius_de_Figueiredo (Acessado em $16 / 09 / 2015)$.

LEIBNIZ, G. W. "Novos Ensaios sobre o Entendimento Humano". (NEEH). In: Os Pensadores: Leibniz. São Paulo: Nova Cultural, 1999.

LEPE-CARRIÓN, P. "Racismo filosófico: el concepto de 'raza' en Immanuel Kant". Filosofia Unisinos, Vol. 15, Nr. 1, pp. 67-83, janeiro/abril 2014. DOI: 10.4013/ fsu.2014.151.05

PURTSCHERT, P. “On the limit of spirit: Hegel's racism revisited". Philosophy and Social Criticism, Vol. 36, Nr. 9, pp. 1039-1051, 2010. DOI: 10.1177/0191453710379029. RORTY, R. "Objetivismo, relativismo e verdade. Escritos filosóficos I". Rio de Janeiro: Relume-Dumará, 1997.

."Filosofia como Espelho da Natureza". Rio de Janeiro: Relume-Dumará, 1995. SAFATLE, V. "Circuito dos Afetos". São Paulo: Cosac Naify, 2015.

SALES-MOLIN, L. "Le code noir". Paris: Presses Universitaires de France, 1987.

TAYLOR, C. "Hegel e a sociedade moderna". Tradução de Luciana Pudenzi. São Paulo: Loyola, 2005.

. “Argumentos filosóficos”. Tradução de A. U. Sobral. São Paulo: Loyla, 2000. 
TERRA, R. R. “Kant racista?”. Coleção CLE, Vol. 57, pp. 299-312, 2010.

TOCQUEVILlE, A. "A democracia na América". Belo Horizonte: Ed. Itatiaia/São Paulo: EdUSP, 1977.

VOLTAIRE. "Essai sur les moeurs et l'esprit des nations". Paris: Garnier, 1963. 